\title{
Application of Institute of Medicine's Gestational Weight Gain Recommendations in Asian Population: A Scoping Review
}

\author{
Hanny L. Zahroh ${ }^{1, *}$, Yenni Zuhairini ${ }^{2,3}$, Siska Wiramihardja ${ }^{2}$, Amillia Siddiq ${ }^{4}$ \\ ${ }^{1}$ General Medicine, Faculty of Medicine, Universitas Padjadjaran, Indonesia \\ ${ }^{2}$ Nutrition Division, Department of Public Health Science, Faculty of Medicine, Universitas Padjadjaran, Indonesia \\ ${ }^{3}$ Nutrition Working Group, Faculty of Medicine, Universitas Padjadjaran, Indonesia \\ ${ }^{4}$ Department of Obstetrics and Gynecology, Faculty of Medicine, Universitas Padjadjaran, Indonesia
}

Received November 4, 2021; Revised January 9, 2022; Accepted January 22, 2022

\section{Cite This Paper in the following Citation Styles}

(a): [1] Hanny L. Zahroh, Yenni Zuhairini, Siska Wiramihardja, Amillia Siddiq, "Application of Institute of Medicine's Gestational Weight Gain Recommendations in Asian Population: A Scoping Review," Universal Journal of Public Health, Vol. 10, No. 1, pp. 145 - 152, 2022. DOI: 10.13189/ujph.2022.100116.

(b): Hanny L. Zahroh, Yenni Zuhairini, Siska Wiramihardja, Amillia Siddiq (2022). Application of Institute of Medicine's Gestational Weight Gain Recommendations in Asian Population: A Scoping Review. Universal Journal of Public Health, 10(1), 145 - 152. DOI: 10.13189/ujph.2022.100116.

Copyright $\mathrm{C} 2022$ by authors, all rights reserved. Authors agree that this article remains permanently open access under the terms of the Creative Commons Attribution License 4.0 International License

\begin{abstract}
Background. Gestational weight gain (GWG) is an important factor of the well-being of both mother and fetus. Latest recommendation by Institute of Medicine (IOM) was issued in 2009 based on women population in United States, and is classified based on World Health Organization (WHO) body mass index (BMI) cutoffs. Recommendation for Asian population is not currently available. This review aims to review the evidence of the application of said guidelines in Asian population. Method. Articles were searched using Google Scholar and PubMed. Articles published in 2016 or above, with single pregnancies and unlimited to pre-pregnancy BMI categories were selected. Of 1,239 potential articles, 29 were chosen for full-text screening and 9 were included in this review. Result. Mixed trends were found when assessing adequacy of GWG in relation to pre-pregnancy BMI. Article analyzing optimal GWG showed a higher and wider range compared to IOM. Inadequate GWG is associated with a higher risk of small for gestational age (SGA) while excessive GWG is associated with large for gestational age (LGA). Significant differences were found when different categorizations of BMI are used with IOM guidelines. Conclusion. Asian women rarely gain adequate weight by IOM standard. This might lead to increased risk of adverse pregnancy outcomes, such as SGA and LGA. Further researches are needed to study appropriate optimal
\end{abstract}

GWG for Asian population, and/or to modify IOM guidelines to be applied better in Asian population.

Keywords Asian, BMI, GWG, IOM, Pregnancy

\section{Introduction}

More than half of the total number of pregnancies worldwide occurs in Asia, where maternal mortality remains a big problem. $(1,2)$ Women nutritional status is closely related to the health of both the mothers and the fetus. Pregnancy outcomes are greatly affected by pre-pregnancy body mass index (BMI) and gestational weight gain (GWG). Women with abnormal BMI index have a higher risk for poor pregnancy outcomes.(3) Prevalence of underweight women $>18$ years of age is the highest in Southeast Asia, and trends also show an increasing number of overweight and obese women per year worldwide.(4)

Gestational weight gain is defined as the weight a woman gains between the time of conception and the onset of labor.(5) It supports the growth and development of the fetus and is affected by a number of factors, such as physiologic, behavior, psychologic, environment, 
socioeconomic and cultural background. Given the importance of GWG to both the mothers and the fetus, recommendations for the total number of GWG have been developed. Institute of Medicine (IOM) first developed the recommendation in 1930, which states that every pregnant woman should gain $6.8 \mathrm{~kg}$. The recommendation was later revised to in 1990 and 2009, with both updates differentiating the total weight needed to gain in respect to the BMI category. The latest recommendation was made in relation to the changes in the women demographic in the United States (US), such as a higher proportion of women from ethnic subgroups, high rates of overweight and obesity, and the increasing age of pregnant women. Contrary to the 1990's recommendation which used BMI categories derived from Metropolitan Life Insurance tables, the 2009's version is based on World Health Organization (WHO) cutoff points, described as below: $<18.5 \mathrm{~kg} / \mathrm{m}^{2}$ (underweight), $18.5-24.9 \mathrm{~kg} / \mathrm{m}^{2}$ (normal weight), $25-29.9$ $\mathrm{kg} / \mathrm{m}^{2}$ (overweight) and $>30 \mathrm{~kg} / \mathrm{m}^{2}$ (obese). The recommendations were as followed: $12,5-18 \mathrm{~kg}$ for underweight women, 11,5-16 kg for normal weight women, $7-11,5 \mathrm{~kg}$ for overweight women, and 5-9 $\mathrm{kg}$ for obese women.(6)

Underweight women are at a higher risk of gaining weigh below the recommended number.(7) This in turn increases the risk of abnormal pregnancy outcomes, namely low birth weight (LBW), or newborns weighing less than 2,500 grams upon birth, (7,8) small for gestational age (SGA), defined as newborns with weights below $10^{\text {th }}$ percentile for gestational age at birth, $(9,10)$ and premature births.(11) In comparison, overweight and obese women are at a higher risk of gaining weight above the recommended number.(10) This puts them at a higher risk of outcomes such as macrosomia, or newborns weighing more than 4000 grams upon birth,(12) large for gestational age, defined as newborns with weights above $90^{\text {th }}$ percentile for gestational age upon birth,(13) cesarean section, gestational hypertension, gestational diabetes mellitus, and prolonged weight retention after birth. $(7,10)$

Institute of Medicine (IOM) 2009 guideline is the most widely accepted recommendation currently, despite them stating that the guidelines are intended to use among women in the United States and in extension, women in other developed countries. The guidelines are not meant to be used in countries where the women population are thinner and shorter relative to the US, or in countries with inadequate obstetric services available. Modifications of the guidelines are also needed for women below 20 years old and women with multiple fetuses.(6). In addition to this, IOM based their guidelines on WHO BMI cutoff points, making it harder to adapt into Asia-Pacific BMI cutoff points, described as below: $<18.5 \mathrm{~kg} / \mathrm{m}^{2}$ as underweight, $18.5-22.9 \mathrm{~kg} / \mathrm{m}^{2}$ as normal weight, $23-24.9 \mathrm{~kg} / \mathrm{m}^{2}$ as overweight, and $>25 \mathrm{~kg} / \mathrm{m}^{2}$ as obese. These distinct cutoff points were developed in 2004 on the grounds that there are variations in body composition, health risks, and fat depositions on people with different racial backgrounds. Moreover, inconsistencies were often found on Asian BMI cutoffs implemented in a country. Consequently, it is still unclear whether IOM guidelines are appropriate to be implemented in Asian countries.(14)

The purpose of this review is to review the evidence of the application of IOM guidelines in Asian population. A review of the evidence of IOM guidelines application in relation to birth weight for gestational age is also attempted.

\section{Methods}

Articles for this review are explored using Google Scholar and PubMed library. The keywords used to search the articles are as followed: "gestational weight gain", "GWG", "Institute of Medicine", "IOM", "Asian", "Ethnicity", "Small for Gestational Age", "SGA", "Large for Gestational Age", "LGA". Only articles published on 2016 or above were selected. Articles with single pregnancies unlimited to pre-pregnancy BMI categories were selected. No systematic reviews, meta-analysis, and RCT were considered into analysis. Only articles published in English were included.

Articles retrieved following this search strategy were initially screened by titles, abstracts and keywords were screened initially. Full-text screenings were done subsequently to determine which articles are qualified to be included in this review. Details of the study - author, country of origin, publication year, study design, sample size, subject characteristics, results and outcomes-were summarized and analyzed using Microsoft Excel 2010. Quality of the studies was assessed using Critical Appraisal Tool from Joanna Briggs Institute (JBI). This review is in line with Preferred Reporting Items for Systematic reviews and Meta-Analyses extension for Scoping Reviews (PRISMA-ScR).(15)

\section{Results}

\subsection{Study Selection}

Figure 1 summarizes the selection process of studies. A total number of articles identified during search is 1,239. Following initial titles, abstract and keywords screening, 643 articles are excluded. Full-text screening was done and yielded 9 final articles to include in this review. 


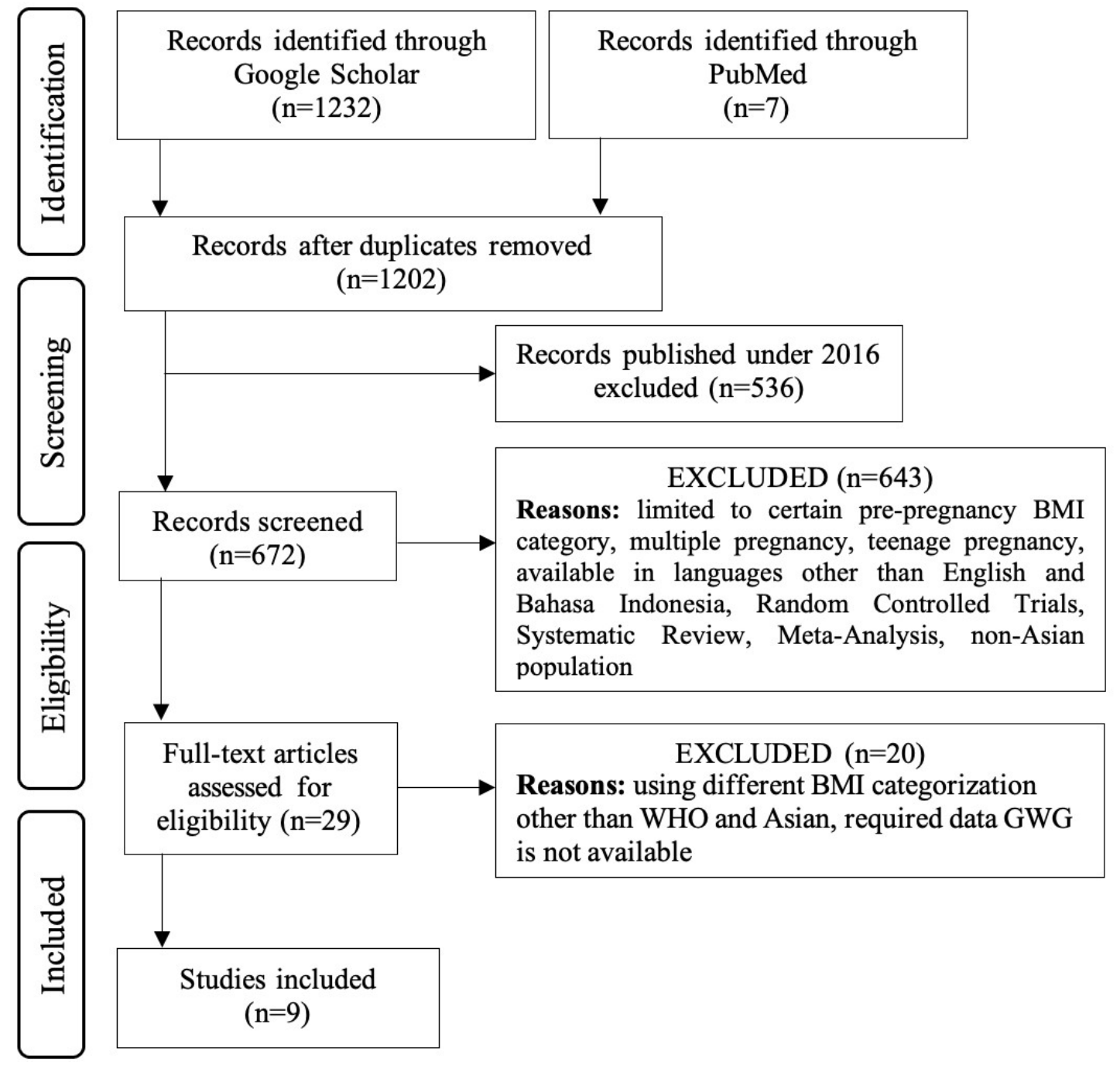

Figure 1. Study selection

\subsection{Study Characteristics}

All nine articles originated from different Asian countries: two from East Asia, $(16,17)$ four from Southeast Asia,(18-21), two from South Asia,(22,23) and one from West Asia.(24) Among them, five are retrospective cohorts, two are prospective cohorts, and two are retrospective cross-sectional.. All retrospective cohorts used past medical records as data source, one prospective cohort used questionnaires,(19) and the other used a mixture of medical records and data taken during visitation.(18) A total of 24,884 women (minimum 180, maximum 13,717) participated in the studies. All studies included both primiparous and multiparous as subjects. Table 1 summarizes study characteristics.

Pre-pregnancy BMI was obtained by self-report in two of the studies $(16,19)$ while the rest of the studies used weight and height measured at first admission at first trimester. A study from Bangladesh (23) only had pre-pregnancy weight data for 419 of the subjects, hence calculation using equation developed based on the subsample data was required for the rest of the subjects. All studies used last measured weight at third trimester to calculate total GWG. A prospective study held in Indonesia (19) used 3 questionnaires to obtain information: questionnaire 1 provided socio-demographic factors, obstetric history, past medical and anthropometric measurements; questionnaire 2 provided antenatal visit outcomes, and questionnaire 3 provided anthropometric measures at 3 pregnancy stages, which were early pregnancy (10-12 weeks), second trimester (22-24 weeks), and third trimester (34-36 weeks) along with intrapartum, delivery, and neonatal outcomes. Subjects of the prospective study held in Singapore (18) were required to have additional visits at 11-14 weeks, 18-22 weeks, 28-32 weeks, and 34-39 weeks alongside routine antenatal visits to measure body weight. 
Table 1. Study characteristics

\begin{tabular}{cclccccc}
\hline Author & Study Design & Country & Year & N & $\begin{array}{c}\text { Maternal } \\
\text { Age } \\
(\mathbf{y e a r})\end{array}$ & $\begin{array}{c}\text { Mean } \\
\text { BMI } \\
\left(\mathbf{k g} / \mathbf{m}^{2}\right)\end{array}$ & $\begin{array}{c}\text { Mean } \\
\mathbf{G W G} \\
\mathbf{( k g})\end{array}$ \\
\hline $\begin{array}{c}\text { Choi et al. } \\
(16)\end{array}$ & $\begin{array}{c}\text { Retrospective } \\
\text { cohort }\end{array}$ & South Korea & 2017 & 2,702 & $32.59 \pm 4.75$ & N/A & N/A \\
\hline $\begin{array}{c}\text { Soltani et al. } \\
(19)\end{array}$ & $\begin{array}{c}\text { Prospective } \\
\text { cohort }\end{array}$ & Indonesia & 2017 & 607 & N/A & $21.3 \pm$ N/A & $10.2 \pm 6.0$ \\
\hline $\begin{array}{c}\text { Bhavadarini et al. } \\
(22)\end{array}$ & $\begin{array}{c}\text { Retrospective } \\
\text { cohort }\end{array}$ & India & 2017 & 2,728 & $27.4 \pm 4$ & $25.1 \pm 4.8$ & $8.8 \pm 4.8$ \\
\hline $\begin{array}{c}\text { He et al. } \\
(18)\end{array}$ & $\begin{array}{c}\text { Prospective } \\
\text { cohort }\end{array}$ & Singapore & 2019 & 724 & $30.6 \pm 5$ & $23.9 \pm 4.6$ & $11.8 \pm 4.5$ \\
\hline $\begin{array}{c}\text { Huang et al. } \\
(17)\end{array}$ & $\begin{array}{c}\text { Retrospective } \\
\text { cohort }\end{array}$ & China & 2018 & 13,717 & $27.3 \pm 4.44$ & $21.3 \pm 3.15$ & $14.4 \pm 5.39$ \\
\hline $\begin{array}{c}\text { Hasan et al. } \\
(23)\end{array}$ & $\begin{array}{c}\text { Retrospective } \\
\text { cohort }\end{array}$ & Bangladesh & 2021 & 1,569 & N/A & N/A & N/A \\
\hline $\begin{array}{c}\text { Papazian et al. } \\
(24)\end{array}$ & $\begin{array}{c}\text { Retrospective } \\
\text { cross-sectional }\end{array}$ & Lebanon & 2017 & 1,000 & $31.5 \pm 4.4$ & $23.0 \pm 3.8$ & $12.07 \pm 6.0$ \\
\hline $\begin{array}{c}\text { Thanaratsiriworakul } \\
\text { et al. (21) }\end{array}$ & $\begin{array}{c}\text { Retrospective } \\
\text { cohort }\end{array}$ & Thailand & 2016 & 1,657 & $26.94 \pm 7.0$ & N/A & $12.9 \pm 5.88$ \\
\hline $\begin{array}{c}\text { Chee et al.(20) } \\
\text { cross-sectional }\end{array}$ & Malaysia & 2019 & 180 & $29.2 \pm 4.3$ & N/A & N/A \\
\hline
\end{tabular}

Table 2. GWG adequacy across studies.

\begin{tabular}{|c|c|c|c|c|c|}
\hline \multirow{2}{*}{ Reference } & \multicolumn{2}{|c|}{ BMI } & \multirow{2}{*}{$\begin{array}{c}\text { Inadequate GWG } \\
(\%)\end{array}$} & \multirow{2}{*}{$\begin{array}{c}\text { Adequate GWG } \\
(\%)\end{array}$} & \multirow{2}{*}{$\begin{array}{c}\text { Excessive GWG } \\
(\%)\end{array}$} \\
\hline & Category & $\%$ & & & \\
\hline \multirow{4}{*}{ Soltani et al. ${ }^{\mathrm{a}}$} & Underweight & $20.1 ; 20.1$ & $47.6 ; 47.6$ & $44.8 ; 44.8$ & $7.6 ; 7.6$ \\
\hline & Normal weight & $65.3 ; 52.9$ & $63.1 ; 61.1$ & $25.6 ; 26.8$ & $11.3 ; 12.1$ \\
\hline & Overweight & $13.5 ; 21.7$ & $37.8 ; 33$ & $43.3 ; 42.6$ & $18.9 ; 24.4$ \\
\hline & Obese & $1.1 ; 5.3$ & $33.3 ; 31$ & $50 ; 34.5$ & $16.7 ; 34.5$ \\
\hline \multirow{4}{*}{ Huang et al. $^{\mathrm{b}}$} & Underweight & $16.48 ; 16.48$ & \multirow{4}{*}{ N/A } & \multirow{4}{*}{$36.41 \%$} & \multirow{4}{*}{ N/A } \\
\hline & Normal weight & $73.73 ; 60.31$ & & & \\
\hline & Overweight & $8.38 ; 13.42$ & & & \\
\hline & Obese & $1.41 ; 9.78$ & & & \\
\hline \multirow{4}{*}{ Bhavadarini et al. } & Underweight & 5.6 & 66.2 & 30.5 & 3.3 \\
\hline & Normal weight & 29 & 69.5 & 23.4 & 7.1 \\
\hline & Overweight & 18.5 & 68.8 & 22.5 & 8.7 \\
\hline & Obese & 46.9 & 34.4 & 37.1 & 28.5 \\
\hline \multirow{4}{*}{ He et al. } & Underweight & 8.1 & 44.1 & 52.5 & 3.4 \\
\hline & Normal weight & 57.2 & 39.1 & 43.7 & 17.2 \\
\hline & Overweight & 23.9 & 16.2 & 38.2 & 45.7 \\
\hline & Obese & 10.8 & 29.5 & 21.8 & 48.7 \\
\hline \multirow{4}{*}{ Hasan et al. } & Underweight & 15.2 & 8.4 & 16.4 & 75.2 \\
\hline & Normal weight & 71.9 & 17.4 & 26.6 & 56 \\
\hline & Overweight \& & & & & \\
\hline & Obese & 13 & 47.3 & 19.2 & 33.5 \\
\hline \multirow{4}{*}{ Papazian et al. } & Underweight & 6.5 & 48.4 & 33.9 & 17.7 \\
\hline & Normal weight & 67.8 & 36.4 & 47.5 & 16.1 \\
\hline & Overweight & 17.9 & 7.3 & 37.3 & 55.4 \\
\hline & Obese & 5.6 & 20.8 & 28.3 & 50.9 \\
\hline \multirow{4}{*}{$\begin{array}{c}\text { Thanaratsiriworakul } \\
\text { et al. }\end{array}$} & Underweight & 19.79 & 43.90 & 34.76 & 21.34 \\
\hline & Normal weight & 58.12 & 35.62 & 37.28 & 27.10 \\
\hline & Overweight & 15.69 & 22.31 & 28.08 & 49.62 \\
\hline & Obese & 6.4 & 27.36 & 28.30 & 44.34 \\
\hline \multirow{4}{*}{ Chee et al. } & Underweight & 14.4 & 46.2 & 15.4 & 38.5 \\
\hline & Normal weight & 56.7 & 36.4 & 47.5 & 16.1 \\
\hline & Overweight & 21.1 & & & \\
\hline & Obese & 7.8 & 17.3 & 5.8 & 76.9 \\
\hline
\end{tabular}

${ }^{\mathrm{a}}$ showed as (\% according to WHO cutoff); ( $\%$ according to Asian cutoff). ${ }^{\mathrm{b}}$ showed as (\% according to WHO cutoff); ( $\%$ according to Asia-Pacific cutoff). 


\subsection{Adequacy of GWG}

Table 2 summarizes the adequacy of gestational weight gain according to IOM. Soltani et al. (19) compared WHO and Asian BMI cutoff. The number of overweight and obese women were significantly higher when using Asian cutoff compared to WHO cutoff. Consequently, $5.5 \%$ of overweight women and $17.8 \%$ of obese women were misclassified as gaining adequate GWG when using WHO cutoff. However, even though the percentage of normal weight women differed by $12.4 \%$, the difference in the percentage of GWG adequacy remained relatively small.

Similar comparison was made in a study by Huang et al. (17) using WHO and Asia-Pacific BMI cutoff. Marked differences were seen in the percentage of every BMI category apart from underweight. Percentage of normal weight women were decreased by $13.42 \%$ while overweight and obese women increased by $5.04 \%$ and $8.36 \%$, respectively. This study also analyzed GWG by percentile and concluded that IOM recommendations, especially the upper limits, are too restrictive for Chinese women. Less than half of all subjects (36.41\%) gained optimal GWG.

The Indian study (22), unlike the others, has the biggest percentage of subjects in obese category $(46.9 \%)$. With the exception of obese, all BMI categories had more than half of the subjects gaining inadequate weight. Contrary to this, the study held in Bangladesh (23) had almost half (47.3\%) of overweight and obese women gaining inadequate weight, while the majority of underweight and normal weight women (56\% and $75.2 \%$, respectively) gaining excessive weight. Three fourths of overweight and obese women in the Malaysian study gained excessive weight.(20)

\subsection{Optimal GWG}

Study from South Korea (16) analyzed optimal GWG ranges within their population by calculating lowest total predicted risk of chosen adverse pregnancy outcomes in relation to GWG. The selected outcomes were SGA, LGA, gestational hypertension and failed labor (patients requiring emergency caesarian section or non-reassuring fetal heart rate). Optimal GWG range did not exceed 5\% increase from the lowest predicted risk. Table 3 summarizes results of this study. All BMI categories were shown to have a higher and wider optimal GWG range compared to IOM guidelines. Optimal GWG for underweight and obese women was outside the range recommended by IOM.

\subsection{Outcomes}

Gestational weight gain relates closely with various pregnancy outcomes. This review focuses solely on SGA and LGA, defined as newborns weighing less than $10^{\text {th }}$ and above $90^{\text {tb }}$ percentile, respectively. $(9,13)$

Majority of infants (82.05\%) in the South Korean study (16) has appropriate weight for gestational age (AGA), followed by SGA (13.25\%) and LGA (4.7\%). This study shown that the risk of SGA decreased $(\mathrm{OR}=0.93,95 \% \mathrm{CI})$ and the risk of LGA increased (OR 1.07, 95\% CI) as the GWG increased by $1 \mathrm{~kg}$.

Study in Bangladesh (23) showed a relatively high number of SGA (38.4\%). Gestational weight gain below IOM recommendations was associated with higher odds of SGA (AOR $=1.3,95 \% \mathrm{CI}$ ), but no association to LGA. In comparison, excessive GWG was associated with LGA $(\mathrm{AOR}=5.9,95 \% \mathrm{CI})$ but no association to SGA. This study also found that GWG of women with optimal outcomes tends to be at the lower of the range recommended by IOM.

Comparison done by Huang et al. (17) found that women with optimal GWG determined by Asia-Pacific cutoffs were at lower risk of having LGA infants, even after adjusted by maternal age, education, smoking status during pregnancy, and parity. However, no significant risk differences were seen for SGA in women with optimal GWG by Asia-Pacific standard compared to WHO standard. Among women with optimal GWG by Asia-Pacific cutoffs, $8.51 \%$ and $8.67 \%$ of infants were SGA and LGA, respectively. Slight differences were seen in women with optimal GWG by WHO cutoff, resulting $8.23 \%$ and $9.96 \%$ of infants being SGA and LGA, respectively. This is supported by a similar comparison by Soltani et al. (19) that found significant differences in these outcomes when using Asian and WHO classifications. The odds of having SGA infants in women with inadequate GWG is increased from 2.79 (WHO) to 3.87 (Asian). Women with excessive GWG also had increased odds of having LGA infants when using Asian classifications - 10.1 compared to 2.21 when using WHO cutoffs.

Table 3. Optimal GWG in South Korean study

\begin{tabular}{ccccc}
\hline BMI & $\mathbf{n}$ & $\mathbf{\%}$ & Optimal GWG & IOM Guidelines \\
\hline Underweight & 440 & 16.28 & $16.7-24.7$ & $12.5-18$ \\
\hline Normal weight & 1459 & 54 & $11.5-21.5$ & $11.5-16$ \\
\hline Overweight & 391 & 14.47 & $8-17.7$ & $7-11.5$ \\
\hline Obese & 412 & 15.25 & $7.5-21.9$ & $5-9$ \\
\hline
\end{tabular}




\subsection{Risk of Bias across Studies}

Differences on BMI categorization were found in selected studies. Four studies $(18,20,21,23,24)$ used WHO cutoffs $-<18.5,18.5-24.9,25-29.9$, and $>30 \mathrm{~kg} / \mathrm{m}^{2}$, two other studies $(16,22)$ used Asia-Pacific cutoffs $-<18.5$, $18.5-22.9,23-24.9$, and $>25$, and $>27 \mathrm{~kg} / \mathrm{m}^{2}$. Indonesian study (19) compared the use of WHO cutoffs and Asian BMI cutoffs - $<18.5,18.5-22.9,23-27.4$, and $>27.5 \mathrm{~kg} / \mathrm{m}^{2}$, while one Chinese study (17) compared WHO cutoffs and Asia-Pacific cutoffs. Different methods of obtaining pre-pregnancy BMI may also cause bias in this study.

\section{Discussion}

\subsection{Summary of Evidence}

Institute of Medicine last updated their GWG guideline in 2009 in response to change in demographic status of women in the United States.(25) This review focuses on the application of IOM guidelines in Asian countries.

The key finding in this study is that pregnant women rarely met the required GWG by IOM standard. While previous researches have proven that lower pre-pregnancy is related to inadequate weight gain and the opposite applied to excessive weight gain, $(10,26)$ mixed trends are shown in selected studies. Research have found that lifestyle intervention is useful in improving lifestyle behavior during pregnancy and reaching appropriate GWG by IOM standard.(27) Pregnant women should be given education about GWG and healthy lifestyle in the future.

Several other studies had tried to propose optimal GWG in Asian countries. $(28,29)$ Results were varied, but generally had a wider range compared to IOM standard. Overweight and obese women were suggested to gain fewer weight than current IOM guidelines. Recent study in Japan also compared Japanese, IOM, and optimal GWG found in study. While IOM guidelines are generally higher than optimal GWG found in the study, Japanese GWG guidelines were much stricter, described as followed: 9-12 $\mathrm{kg}$ for underweight, $7-12 \mathrm{~kg}$ for normal and overweight, and no weight gain for obese women.(29) The majority of Asian countries currently have no official GWG guidelines and researches regarding optimal GWG are limited. Future research for optimal weight gain in different Asian countries is needed.

Relations between pre-pregnancy BMI, gestational weight gain, and birth weight for gestational age were further highlighted in this review. Women gaining weight below IOM standard have a higher risk of having SGA infants. This supports recent researches that found that GWG below IOM standard are related with increased risk of SGA, especially in underweight women. $(7,11,26)$ Previous researches also showed relationships between inadequate GWG to low birth weight and preterm birth. $(7,10,11)$ One research found that women who gained weight under $10 \mathrm{~kg}$ had the highest risk of preterm birth.(11) In comparison, it is founded that women gaining weight above IOM standard are at risk of having LGA infants. This is consistent with findings in several other research, along with risks of having macrosomic infants, gestational diabetes mellitus, and gestational hypertension. $(7,10,30)$

Using other BMI categorizations in accordance with IOM guidelines resulted in differences. Body mass index cutoffs often used in Asia have lower limit for overweight and obese. $(6,31,32)$ The reason for this distinction is that Asians have a higher risk for cardiovascular diseases in lower BMI index compared to non-Asians.(33) Misclassification of overweight and obese women into lower BMI groups might cause them to gain more weight than needed in order for them to reach adequate weight gain by IOM standard. These prompt further research in Asian population to determine how to best modify IOM guidelines to BMI cutoffs used in Asian countries.

\subsection{Strength and Limitations}

The strengths of this review are as followed. (1) All selected studies are from different Asian countries to better represent the Asian women population. (2) Studies are selected by scouring two comprehensive databases. (3) All selected studies were cohort with primarily reliable source of data. (4) Previous systematic review by Arora et al.(34) compared GWG among healthy pregnant Asian women to IOM recommendations, but did not compare BMI categories better in Asian population and did not include studies that analyzed optimal GWG in their population. Hence this review succeeds in highlighting the knowledge gap existed within this topic.

Several limitations were to be noted in this review. The inconsistencies of BMI categorization used in the studies were one of the important limitations of this review. This review only included studies from West, East, South and Southeast Asia. Unsuccessful attempts were done in order to search for studies from Central Asia. Only South Korean study calculated optimal GWG.

\section{Conclusion}

Asian women were found to rarely gain adequate weight by IOM standard. This might lead to increased risk of adverse pregnancy outcomes, such as SGA and LGA. Further researches are needed to study appropriate optimal GWG for Asian population, and/or to modify IOM guidelines to be applied better in Asian population.

\section{Acknowledgment}

We thank Prof. Dr. Rina Indiastuti, M.SIE as Rector of Universitas Padjadjaran, Prof. Dr. Yudi Mulyana Hidayat, dr., Sp.OG(K) as Dean of Faculty of Medicine, Dr. 
Mohammad Ghozali, dr., M.Sc as Head of Medicine major. We also thank Amilia Siddiq, dr., Sp.OG(K), M.Si for contributing thoughtful inputs during preparation of this study, and to friends and families who support us always in the making of this review.

\section{REFERENCES}

[1] Sedgh G, Singh S, Hussain R. Intended and Unintended Pregnancies Worldwide in 2012 and Recent Trends. Stud Fam Plann [Internet]. 2014;45(3):301-14. Available from: https://onlinelibrary.wiley.com/doi/epdf/10.1111/j.1728-44 65.2014.00393.x?src=getftr

[2] World Health Organization. WHO Fact Sheet of Maternal Mortality [Internet]. 2019 [cited 2021 May 1]. Available from:

https://www.who.int/news-room/fact-sheets/detail/materna 1-mortality

[3] World Health Organization. Nutrition of women in the preconception period, during pregnancy and the breastfeeding period [Internet]. World Health. 2012. Available from: http://apps.who.int/gb/ebwha/pdf_files/W HA65/A65_12-en.pdf

[4] World Health Organization. Body Mass Index (BMI) Global Health Observatory data repository [Internet]. 2016 [cited 2021 Apr 29]. Available from: https://apps.who.int/gho/data/node.main.BMIANTHROPO METRY?lang=en

[5] Batashki I, Topalovska D, Milchev N, Uchikova E, Terzhumanov R. Obesity and pregnancy [Internet]. Vol. 45, Akusherstvo i ginekologiia. Elsevier Inc.; 2006. 14-18 p. Available from:https://doi.org/10.1016/B978-0-323-48559 $-3.00013-0$

[6] Institute of Medicine (US) and National Research Council (US) Committee to Reexamine IOM Pregnancy Weight Guidelines. Weight Gain during Pregnancy: Reexamining the Guidelines. Rasmussen KM, Yaktine AL, editors. Washington, D.C: The National Academies Press; 2009.

[7] Zhao R, Xu L, Wu ML, Huang SH, Cao XJ. Maternal pre-pregnancy body mass index, gestational weight gain influence birth weight. Women and Birth [Internet]. 2018;31(1):e20-5. Available from: http://dx.doi.org/10.1016/j.wombi.2017.06.003

[8] Cutland CL, Lackritz EM, Mallett-Moore T, Bardají A, Chandrasekaran R, Lahariya C, et al. Low birth weight: Case definition \& guidelines for data collection, analysis, and presentation of maternal immunization safety data. Vaccine [Internet]. 2017;35(48):6492-500. Available from: https://doi.org/10.1016/j.vaccine.2017.01.049

[9] Schlaudecker EP, Munoz FM, Bardají A, Boghossian NS, Khalil A, Mousa H, et al. Small for gestational age: Case definition \& guidelines for data collection, analysis, and presentation of maternal immunisation safety data. Vaccine [Internet]. 2017;35(48):6518-28. Available from: https://doi.org/10.1016/j.vaccine.2017.01.040

[10] Goldstein RF, Abell SK, Ranasinha S, Misso M, Boyle JA,
Black $\mathrm{MH}$, et al. Association of gestational weight gain with maternal and infant outcomes: A systematic review and meta-analysis. JAMA - J Am Med Assoc. 2017;317(21):2207-25.

[11] Han Z, Lutsiv O, Mulla S, Rosen A, Beyene J, McDonald SD. Low gestational weight gain and the risk of preterm birth and low birthweight: A systematic review and meta-analyses. Acta Obstet Gynecol Scand. 2011;90(9):935-54.

[12] The American College of Obstetricians and Gynecologists. Macrosomia: ACOG Practice Bulletin, Number 216 Committee on Practice Bulletins-Obstetrics. Obstet Gynecol. 2020;135(1):e18-35.

[13] World Health Organization. Physical status: The use and interpretation of anthropometry. Vol. 1. Benteli; 1995.

[14] Li C, Liu Y, Zhang W, Obukhov AG. Joint and independent associations of gestational weight gain and prepregnancy body mass Index with outcomes of pregnancy in chinese women: a retrospective cohort study. PLoS One. 2015;10(8):e0136850

[15] Tricco AC, Lillie E, Zarin W, O’Brien KK, Colquhoun H, Levac D, et al. PRISMA extension for scoping reviews (PRISMA-ScR): Checklist and explanation. Ann Intern Med. 2018;169(7):467-73.

[16] Choi SK, Lee G, Kim YH, Park IY, Ko HS, Shin JC. Determining optimal gestational weight gain in the Korean population: A retrospective cohort study. Reprod Biol Endocrinol. 2017;15(1):1-7.

[17] Huang X, Tan H, Cai M, Shi T, Mi C, Lei J. Gestational weight gain in Chinese women -- Results from a retrospective cohort in Changsha, China. BMC Pregnancy Childbirth. 2018;18(1):1-9.

[18] He S, Allen JC, Razali NS, Win NM, Zhang JJ, Ng MJ, et al. Are women in Singapore gaining weight appropriately during pregnancy: A prospective cohort study. BMC Pregnancy Childbirth. 2019;19(1):4-11.

[19] Soltani H, Lipoeto NI, Fair FJ, Kilner K, Yusrawati Y. Pre-pregnancy body mass index and gestational weight gain and their effects on pregnancy and birth outcomes: A cohort study in West Sumatra, Indonesia. BMC Womens Health. 2017;17(1):1-12.

[20] Chee WF, Si YM, Siew CY. Factors Associated with Rates of Gestational Weight Gain among Pregnant Women in Batu Pahat District of Johor state, Malaysia. Malaysian J Med Heal Sci. 2019;15(SP1):2636-9346.

[21] Thanaratsiriworakul K, Suriya N, Sananpanichkul P. Comparison of Gestational Weight Gain Recommendations between Study from Thai Population and U.S. Institute of Medicine. Thai J Obstet Gynaecol Thai J Obs Gynaecol. 2016;24(3):161-8.

[22] Bhavadharini B, Anjana RM, Deepa M, Jayashree G, Nrutya S, Shobana M, et al. Gestational weight gain and pregnancy outcomes in relation to body mass index in Asian Indian women. Indian J Endocrinol Metab. 2017;21(4):588-93.

[23] Hasan SMT, Khan MA, Ahmed T. Institute of medicine recommendations on the rate of gestational weight gain and perinatal outcomes in rural Bangladesh. Int J Environ Res 
Public Health. 2021;18(12).

[24] Papazian T, Tayeh GA, Sibai D, Hout H, Melki I, Khabbaz LR. Impact of maternal body mass index and gestational weight gain on neonatal outcomes among healthy Middle-Eastern females. PLoS One. 2017;12(7):1-13.

[25] Institute of Medicine (US) and National Research Council (US) Committee to Reexamine IOM Pregnancy Weight Guidelines. Weight Gain in Pregnancy. Vol. 15, Journal of Obstetric, Gynecologic, \& Neonatal Nursing. 2009.

[26] Truong YN, Yee LM, Caughey AB, Cheng YW. Weight gain in pregnancy: Does the Institute of Medicine have it right? Am J Obstet Gynecol [Internet]. 2015;212(3):362.e1-362.e8. Available from: http://dx.doi.org/10.1016/j.ajog.2015.01.027

[27] Așc1 Ö, Rathfisch G. Effect of lifestyle interventions of pregnant women on their dietary habits, lifestyle behaviors, and weight gain: a randomized controlled trial. J Health Popul Nutr. 2016;35:7.

[28] Zheng W, Huang W, Zhang L, Tian Z, Yan Q, Wang T, et al. Suggested Gestational Weight Gain for Chinese Women and Comparison with Institute of Medicine Criteria: A Large Population-Based Study. Obes Facts. 2021;14(1):19.

[29] Morisaki N, Nagata C, Jwa SC, Sago H, Saito S, Oken E, et al. Pre-pregnancy BMI-specific optimal gestational weight gain for women in Japan. $\mathrm{J}$ Epidemiol [Internet]. 2017;27(10):492-8. Available from: http://dx.doi.org/10.1016/j.je.2016.09.013

[30] Davies GAL, Maxwell C, McLeod L, Gagnon R, Basso M, Bos H, et al. Obesity in Pregnancy. J Obstet Gynaecol Canada [Internet]. 2010;32(2):165-73. Available from: http://dx.doi.org/10.1016/S1701-2163(16)34432-2

[31] Goldstein RF, Harrison CL, Teede HJ. Editorial: The importance of gestational weight gain. Obes Rev [Internet]. 2020; 21(10):2-3. Available from: wileyonlinelibrary.com/journal/obr

[32] Rasmussen KM, Catalano PM, Yaktine AL. New guidelines for weight gain during pregnancy: what obstetrician/gynecologists should know. Curr Opin Obstet Gynecol [Internet]. 2009;21(6):521-6. Available from: https://journals.lww.com/co-obgyn/Abstract/2009/12000/N ew_guidelines_for_weight_gain_during_pregnancy_.12.as $\mathrm{px}$

[33] WHO Expert Consultations. Appropriate body-mass index for Asian populations and its implications. Lancet [Internet]. 2004;363:157-63. Available from: www.thelancet.com

[34] Arora P, Tamber Aeri B. Gestational Weight Gain among Healthy Pregnant Women from Asia in Comparison with Institute of Medicine (IOM) Guidelines-2009: A Systematic Review. J Pregnancy [Internet]. 2019;2019. Available from: http://doi.org/10/1155/2019/38449596 